\title{
Occurrence of Delayed Leaf Senescence of Soybean Caused by Rhizoctonia Aerial Blight in Japan
}

\author{
Toshiaki TAKEHARA ${ }^{1 *}$, Sunao OCHI ${ }^{2,4}$, Yasuo OHTO $^{3,4}$, Shigeo NAITO ${ }^{2,6}$, \\ Hiroyoshi INOUE ${ }^{1,5}$ and Hisayoshi MIYAGAWA ${ }^{1}$ \\ ${ }^{1}$ Western Region Agricultural Research Center, National Agriculture and Food Research \\ Organization (NARO) (Fukuyama, Hiroshima 721-8514, Japan) \\ ${ }^{2}$ Graduate School of Agriculture, Hokkaido University (Sapporo, Hokkaido 060-0808, Japan) \\ ${ }^{3}$ Tohoku Agricultural Research Center, National Agriculture and Food Research Organization \\ (NARO) (Morioka, Iwate 020-0198, Japan)
}

\begin{abstract}
In 2004, an outbreak of Rhizoctonia aerial blight on soybeans planted after rice in paddy fields in Hiroshima Prefecture, Japan was also associated with delayed leaf senescence (DLS, or green stem/ bean syndrome). The isolated Rhizoctonia solani was characterized as anastomosis group AG-1 IA, identical to that of the $R$. solani causing rice sheath blight. The relationship between aerial blight and soybean DLS, which are also problems in Japan, was examined through field inoculation testing of the rice sheath blight pathogen on soybean plants. In some plots, fungicides (azoxystrobin, flutolanil or validamycin A) were sprayed on the soybean foliage after inoculation, and some plots received frequent overhead irrigation to promote disease. There was a high incidence of the disease and DLS in the inoculated and frequently irrigated plots without the application of fungicide. Without fungicides, the yield from diseased soybeans was $12-35 \%$ lower than that in noninoculated control plots. The fungicide sprays described above were effective in controlling DLS and yield loss from the disease. We thus clearly showed that Rhizoctonia aerial blight of soybean caused by the rice sheath blight pathogen is at least one of the causes of soybean DLS. Frequent rainfall is likely to promote the disease and resulting DLS.
\end{abstract}

Discipline: Plant disease

Additional key words: fungicide, green bean/stem syndrome, ISSR-PCR, Rhizoctonia solani AG-1

IA, rice sheath blight

\section{Introduction}

In Japan, paddy fields are the main production sites for soybeans, and soybeans are often rotated with rice (the staple food of the Japanese people), wheat, or barley. In 2004, there was a severe outbreak of unfamiliar disease with foliar blight on rotational soybeans (cultivars Sachiyutaka and Akishirome) in paddy fields located in Hiroshima Prefecture, Japan (with about 88 ha being damaged). From mid-August to September, the leaves of the middle to lower parts of the soybean plants became rotten (Fig. 1 a, b) while the upper leaves remained healthy, with the disease developing inside the canopy. Web-like mycelia were seen on wet plant parts (Fig. 1 b, c), and pods were also rotten in plants with severe symptoms (Fig. $1 \mathrm{~d}$ ). Later during the harvest season in late October, the soybeans exhibited symptoms of delayed leaf senescence (DLS) (Fig. 1 h). Abundant sclerotia brown in color and $1-3 \mathrm{~mm}$ in diameter (Fig. $1 \mathrm{e}, \mathrm{f}, \mathrm{g}$ ) were seen on the stems, petioles, and pods of the plants with DLS. These features of disease development were similar to those of previously reported Rhizoctonia aerial blight of soybean caused by Rhizoctonia solani in Japan (Tsuzaki et al. 1995).

DLS (also called delayed stem senescence, green stem/ bean syndrome, or green stem disorder) of soybeans has been a serious problem in Japan. Soybean plants with DLS

Present address:

${ }^{4}$ Central Region Agricultural Research Center, National Agriculture and Food Research Organization (Tsukuba, Ibaraki 305-8666, Japan)

${ }^{5}$ Kyushu Okinawa Agricultural Research Center, National Agriculture and Food Research Organization (Koshi, Kumamoto 8611192, Japan)

${ }^{6}$ Professor emeritus, Hokkaido University (Sapporo, Hokkaido 060-0808, Japan)

*Corresponding author: e-mail toshi@affrc.go.jp

Received 27 March 2015; accepted 3 November 2015. 


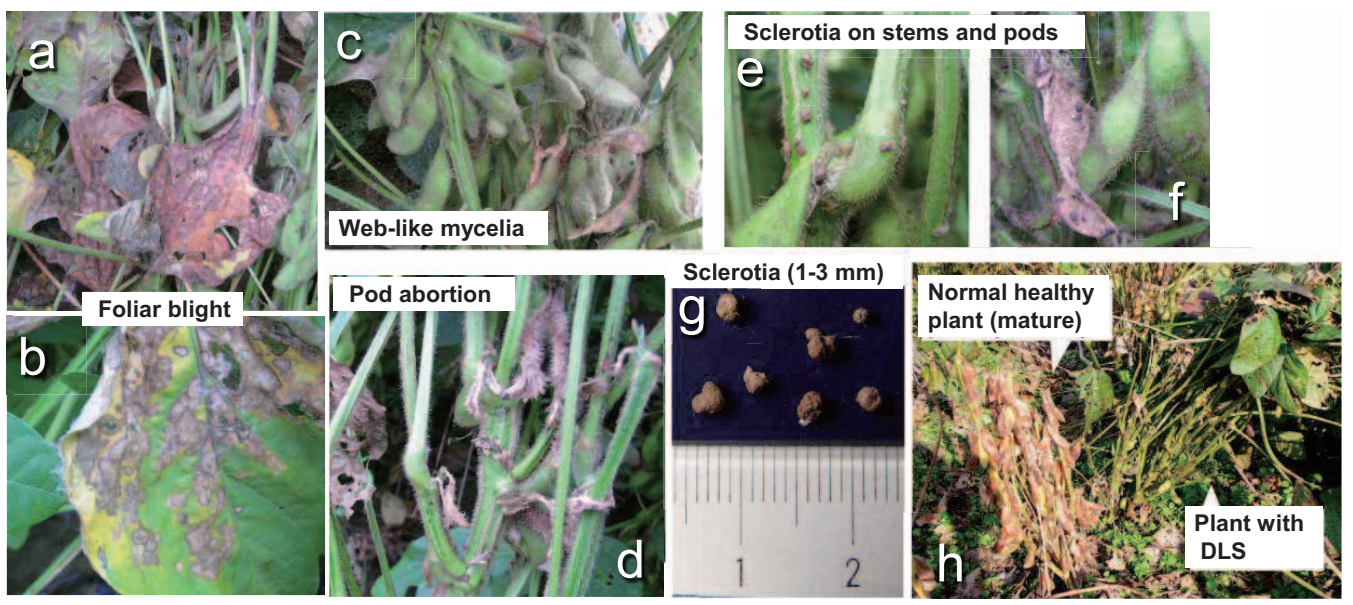

Fig. 1. Symptoms of Rhizoctonia aerial blight in the soybean field and sclerotia on soybeans
(a) Leaf blight symptom (greenish gray to brown)
(b) Leaf spot symptom on soybean (Note the mycelia bridging to the next leaf.)
(c) Web-like mycelia seen in wet conditions
(d) Pod abortion due to the disease
(e) Sclerotia on soybean stems
(f) Sclerotia on soybean pods
(g) Sclerotia from soybean 1-3 $\mathrm{mm}$ in diameter
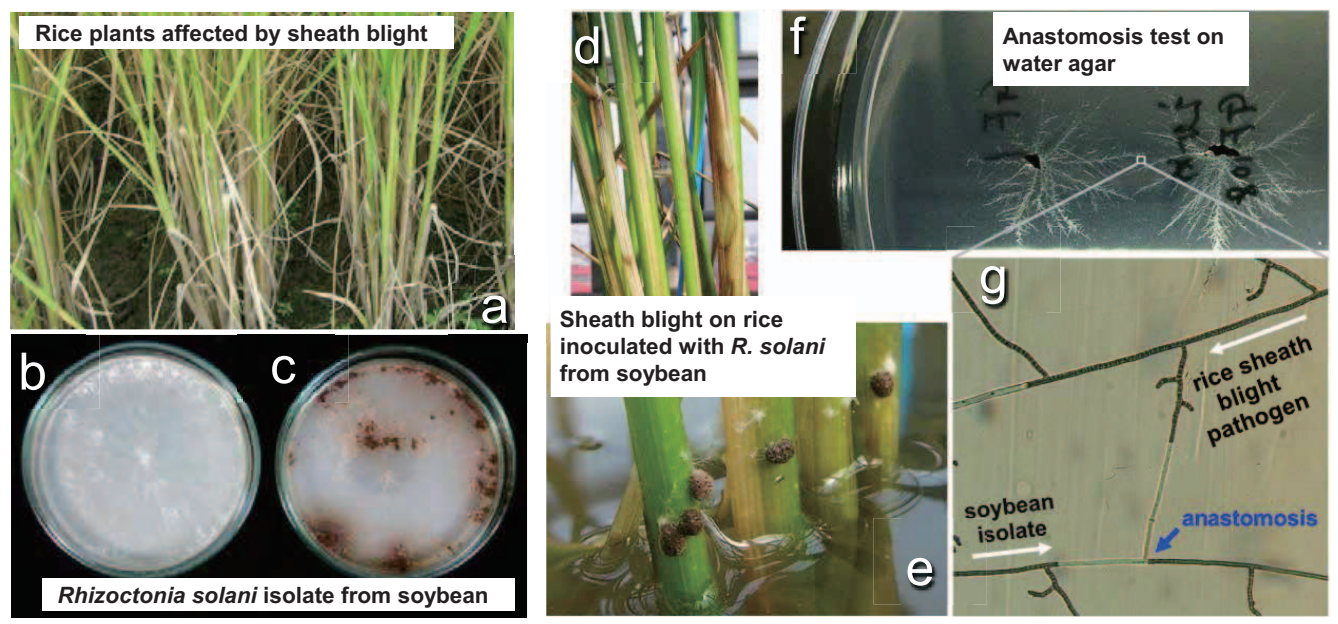

Fig. 2. Relationship between Rhizoctonia solani isolates from soybean and rice
(a) Rice plants affected by sheath blight in a farmer's field
(b) Morphology of R. solani isolate from sclerotia on soybean (young culture on a PSA plate)
(c) Morphology of $R$. solani isolate from sclerotia on soybean (old culture with sclerotia on a PSA plate)
(d) Sheath blight symptom on rice inoculated with $R$. solani from soybean
(e) Sclerotia formed on rice inoculated with $R$. solani from soybean
(f) Anastomosis test of two $R$. solani isolates on water agar
(g) Anastomosis (imperfect fusion) of two R. solani isolates

show delayed maturation and stay green even at harvest time, hindering timely harvesting and often causing stains from the green sap on soybean seeds after threshing. The cause of DLS is not well understood, although some studies indicate a difference in the severity of DLS among soybean cultivars, and some factors such as decrease of pods are associated with DLS (Crafts-Brandner et al. 1984, Matsumoto et al. 1986, Isobe et a1. 2014, Fujii et al. 2015).
In this case of Hiroshima, all fields with the disease had produced rice before soybeans. Rhizoctonia aerial blight (or Rhizoctonia foliar blight, web blight) of soybean (Atkins Jr. \& Lewis 1954, Wu \& Lin 1967) caused by Rhizoctonia solani Kühn is sometimes a serious problem in Japan (Kurata 1960, Naito \& Kanematsu 1994, Tsuzaki et al. 1995, Arai et al. 2000), and there have been suggestions that the pathogen of the disease may be identical to the 
Table 1. Collection information for isolates of Rhizoctonia solani used and results of anastomosis and pathogenicity tests

\begin{tabular}{|c|c|c|c|c|c|}
\hline \multirow{2}{*}{ Isolate name } & \multirow{2}{*}{ Collection site } & \multirow{2}{*}{ Original host } & \multirow{2}{*}{$\begin{array}{l}\text { Anastomosis with rice } \\
\text { sheath blight pathogen }\end{array}$} & \multicolumn{2}{|c|}{ Pathogenicity } \\
\hline & & & & Soybean & Rice \\
\hline GF1 & Miyoshi City, Hiroshima Pref. & Soybean & + & + & + \\
\hline GFT4 & Miyoshi City, Hiroshima Pref. & Soybean & + & + & + \\
\hline GF98 & Miyoshi City, Hiroshima Pref. & Soybean & + & NT & NT \\
\hline GF18 & Sera Discrict, Hiroshima Pref. & Soybean & + & + & + \\
\hline GF99 & Onomichi City, Hiroshima Pref. & Soybean & + & + & NT \\
\hline GFT1 & Yamagata District, Hiroshima Pref. & Soybean & + & + & + \\
\hline RA98-01 & Shimane Pref. & Rice & + & + & + \\
\hline RA02-06 & Shimane Pref. & Rice & NT & + & + \\
\hline RA02-13 & Shimane Pref. & Rice & NT & + & NT \\
\hline Control (mock) & & & & - & - \\
\hline
\end{tabular}

NT $=$ not tested

pathogen of rice sheath blight (Fig. 2 a, d), Rhizoctonia solani anastomosis group AG-1 IA (Tsuzaki et al. 1995, Arai et al. 2000). Thus, in order to clarify the cause of the disease in Hiroshima, and investigate the relationship between the disease and soybean DLS, we conducted potand field-inoculation tests. Parts of this report were presented at meetings of the Phytopathological Society of Japan (Takehara et al. 2005, 2006; Ochi et al. 2005).

\section{Materials and methods}

\section{Fungal isolates}

Fungal isolates were obtained from sclerotia on diseased soybean plants as follows: Sclerotia on stems or pods were surface-disinfected in $70 \%$ ethanol, washed in sterile distilled water, placed on water agar medium containing $250 \mathrm{mg}$ chloramphenicol per liter or on acidified water agar medium containing $50 \mathrm{mg}$ of streptomycin sulfate per liter, and then incubated for 3-5 days at $25^{\circ} \mathrm{C}$, before hyphal tip transfer to PSA (potato sucrose agar) slants. Some sclerotia were placed on the isolation medium without surface disinfection. Dr. Jun Isota of the Shimane Agricultural Technology Center in Japan contributed strains of rice sheath blight pathogens RA98-01, RA02-06, and RA02-13.

\section{Pathogenicity test of isolates and cross inoculation on soybean and rice}

The pathogenicity of fungal isolates on soybeans was checked by excising mycelial blocks of isolates grown on PSA plates, and then attaching the blocks with adhesive tape to the leaves of soybean plants (cv. Sachiyutaka and Akishirome) 21-34 days after seeding in commercial nursery soil. Two plants were used per isolate. Inoculated plants were covered with a transparent plastic bag to maintain humidity and then incubated in a growth chamber at $28^{\circ} \mathrm{C}$ (12 h light, $12 \mathrm{~h}$ dark). Leaves with lesions were used to reisolate the fungus. Strains of the rice sheath blight pathogen were also tested for pathogenicity in the same way.

The pathogenicity of the isolates was checked on rice (cv. Hinohikari) by inserting a mycelial plug between a rice leaf sheath and culm above water 61 days after seeding in commercial nursery soil in Wagner pots. Three plants were inoculated per pot, with three pots being used per isolate. Plants in a pot were then covered with a transparent plastic bag to maintain humidity and held in a glass house at $16-32^{\circ} \mathrm{C}$. The temperature around the shaded rice plants was $20-28^{\circ} \mathrm{C}$. Table 1 lists the isolates (Rhizoctonia solani) that were selected for further testing after the pathogenicity tests.

\section{Characterization of isolates}

(1) Number of nuclei

For identifying the Rhizoctonia isolates, hyphal cells were stained with acridine orange ( $5 \mu \mathrm{g}$ of acridine orange in $50 \mathrm{~mL}$ of distilled water) for $1 \mathrm{~min}$ to count the number of nuclei. Stained hyphae were washed well with distilled water, and nuclei in at least 10 cells per isolate were counted using fluorescence microscopy. The dyed mycelial tips were observed using a BX-50 microscope (Olympus, Tokyo, Japan) and a reflected light fluorescence attachment: BX-FLA (Olympus, Tokyo, Japan) equipped with the WBV filter set (Exciter filter: BP400-440, Barrier filter: BA475).

(2) Colony morphology

Rhizoctonia solani is subdivided into anastomosis groups (AGs) based on the presence and type of hyphal fusion among isolates (Ogoshi 1976, 1987). Because colony morphology (Watanabe \& Matsuda 1966) is related to the AG, we can narrow down the candidate AGs based on 
the color and shape of the colony, and the size of sclerotia. Thus, the isolates were incubated on PSA plates for 10 days at room temperature to assess colony morphology. Growth at $35^{\circ} \mathrm{C}$ was also tested.

(3) Hyphal fusion test

Sample isolates were then tested for hyphal fusion with candidate AG strains AG-1 IA, AG-1 IB, and AG-1 IC. Because Naito \& Kanematsu (1994) reported that AG-2-3 was isolated from foliar blight lesions of soybean in Japan, AG-2-3 isolate was included in the hyphal fusion test (Table 2), but AG-1 ID, AG-1 IE, and AG-1 IF, which are not reported in Japan, were excluded. The two isolates in the test were placed $3 \mathrm{~cm}$ apart on a water agar plate (Fig. 2 f) and incubated for several days. Sites where hyphae from different isolates crossed were examined with a light microscope for hyphal fusion (anastomosis) (Fig. 2 g) according to Carling et al. (1988).

(4) Inter simple sequence repeat PCR (ISSR-PCR)

ISSR-PCR is useful for analyzing genetic variation among the subgroups of $R$. solani AG-2 (Kiyoshi et al. 2005). To distinguish among AG-1 IA, IB, and IC, we used ISSR-PCR, basically according to the method prescribed by Kiyoshi et al. (2005) with primer CGA (5'-CGACGACGACGACGA-3'), which stably amplified DNA fragments and showed polymorphism among AG-1 subgroups in our preliminary test. Table 2 lists the isolates used for ISSR-PCR. The PCR reaction mixtures contained 5 U of Taq DNA polymerase (Takara Bio Inc., Otsu, Japan), $50 \mathrm{mM} \mathrm{KCl}, 10 \mathrm{mM}$ Tris-HCl (pH 8.4), $1.5 \mathrm{mM} \mathrm{MgCl}_{2}$, dNTP mixture ( $250 \mu \mathrm{M}$ each), $0.4 \mu \mathrm{M}$ primer, and $75 \mathrm{ng}$ of template DNA. The final volume was adjusted to $50 \mu \mathrm{l}$ with sterile water. The reaction mixtures were initially denatured in the thermal cycler at $94^{\circ} \mathrm{C}$ for $2 \mathrm{~min}$, then processed by 30 cycles of denaturation at $94^{\circ} \mathrm{C}$ for $40 \mathrm{~s}$, with annealing at $61^{\circ} \mathrm{C}$ for $1 \mathrm{~min}$ and extension at $72^{\circ} \mathrm{C}$ for 1 min. Final elongation was achieved at $72^{\circ} \mathrm{C}$ for $5 \mathrm{~min}$. Amplified fragments were separated by electrophoresis on $1.5 \%$ agarose gels and visualized by ethidium bromide staining.

\section{Field inoculation test to reproduce disease and DLS}

Soybeans (cv. Sachiyutaka) were sown in an experimental field at the Western Region Agricultural Research Center in Fukuyama, Japan on 14 July. Each plot was 12 $\mathrm{m}^{2}(3 \times 4 \mathrm{~m})$ in size and each treatment consisted of three replications of the plots. Soybean seeds were sown by hand (two seeds per hole) at inter-row spacing of $70 \mathrm{~cm}$ and intrarow spacing of $20 \mathrm{~cm}$. Seedlings were thinned on 31 July to produce one seedling per stand.

After flowering, the plants were inoculated with isolate RA98-01 on 23 August, by scattering inoculum cultured on a mixture of wheat bran, rice chaff, and rice straw (Fig. 3 a, b) over the top of the plants (310 g/plot). Six days
Table 2. Standard isolates used to identify anastomosis groups

\begin{tabular}{lll}
\hline \hline AG & Isolate & Purpose \\
\hline -1 IA & CS-GI & Hyphal fusion test \\
-1 IA & H5-502 & ISSR \\
-1 IA & C-325 & ISSR \\
-1 IA & IA-61 & ISSR \\
-1 IB & Rh277 & ISSR \\
-1 IB & U8 & ISSR \\
-1 IB & B19 & Hyphal fusion test, ISSR \\
-1 IC & BV7 & Hyphal fusion test, ISSR \\
-1 IC & $80 F-2$ & ISSR \\
-1 IC & RH28 & ISSR \\
-2-3 & r-6 s-1 & Hyphal fusion test \\
\hline
\end{tabular}

Isolates were preserved at Hokkaido Univeristy.
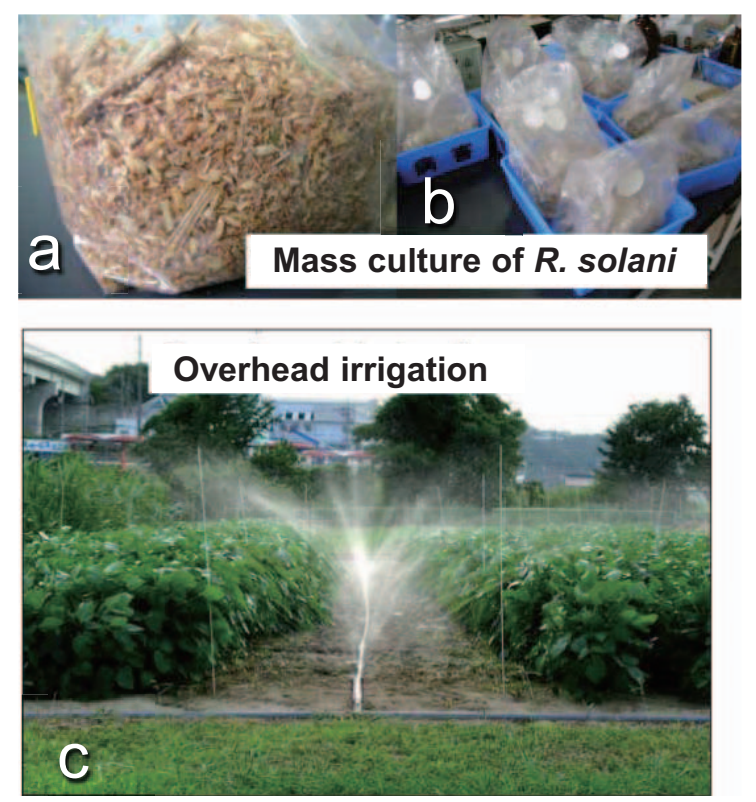

Fig. 3. Mass culture of Rhizoctonia solani for field inoculation, and overhead irrigation to soybeans

later, chemical fungicides (azoxystrobin, flutolanil or validamycin A) were sprayed on soybean foliage at the makerrecommended standard concentration and quantity. These fungicides were used due to being registered for rice against sheath blight and for soybeans against diseases other than aerial blight. In some plots, overhead irrigation was frequently applied (about $24 \mathrm{~mm}, 3-5$ days per week) from the day of inoculation until early October to promote disease development (Fig. 3 c). Each plant was rated for disease severity in September using an index from 0 to 4 (0: no symptoms; 1: some leaf lesions; 2 : some dropped leaves; 3 : some rotted pods; 4 : most pods rotten). At harvest in late October, each plant was rated for DLS severity using an index from 0 to 4 ( 0 : brown to pale brown stem (normal 
senescence); 1: cream to pale green stem; 2: green stem; 3: green stem and some leaves remaining; 4 : one-third of all leaves remaining).

\section{Results}

\section{Pathogenicity test of isolates and cross inoculation on soybean and rice}

Of 119 fungal isolates obtained from sclerotia, 14 isolates of diverse morphology were selected and used for inoculation tests. Of these 14 isolates, nine were pathogenic on soybean leaves, causing distinct, brown, wet or dry lesions. The nine pathogenic isolates all had similar colony morphology and hyphae characteristic of Rhizoctonia sp. The other five isolates did not cause any symptoms and were not Rhizoctonia sp. Six of the pathogenic isolates from soybean, as well as the rice sheath blight pathogen contributed from Shimane Prefecture, were used in further testing (Table 1). Rice plants inoculated with the Rhizoctonia isolates developed typical sheath blight symptoms two days after inoculation and later (Fig. 2 d, e). On inoculated soybeans and rice plants, aerial mycelia of Rhizoctonia were visible during disease development, and eventually sclerotia formed on both hosts. The same Rhizoctonia was reisolated from the lesions of inoculated leaves, thus fulfilling Koch's postulates. Little difference in virulence was detected among the isolates regardless of the collection site, and no difference in susceptibility was observed between the inoculated soybean cultivars (Sachiyutaka and Akishirome).

\section{Characterization of isolates}

(1) Number of nuclei

Many cells of the sample isolates had more than three nuclei. The hyphae of these isolates had dolipore septa and no clamp connections. Under the criteria established by Domsch et al. (1993), the isolates belonged to Rhizoctonia solani.

(2) Colony morphology

The colony color of the isolates was initially white, then turned brownish-red, and the isolates formed abundant blackish brown sclerotia 1-3 mm in diameter (Fig. $2 \mathrm{~b}, \mathrm{c}$ ). Because these isolates grew at $35^{\circ} \mathrm{C}$, we assumed these sample isolates belong to $R$. solani cultural type IA (Watanabe \& Matsuda 1966).

(3) Hyphal fusion test

Imperfect fusion was often observed between the sample isolates and the AG-1 subgroup testers (Fig. 2 g). However, the sample isolates had no reaction with isolates of AG-2-3. Therefore, these isolates were assumed to belong to AG-1.

(4) Inter simple sequence repeat PCR (ISSR-PCR)

Each of the band patterns from ISSR-PCR for AG-1 IA, IB, and IC was characteristic (Fig. 4). The band pattern

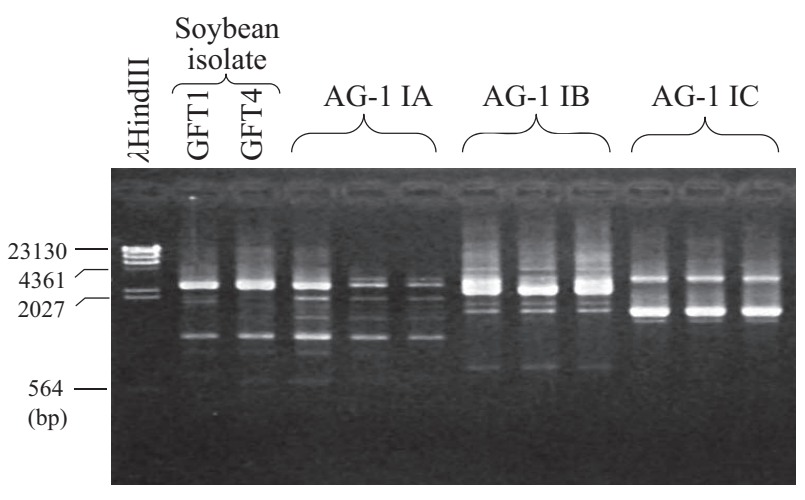

Fig. 4. Band patterns from Inter simple sequence repeat PCR (ISSR-PCR) of soybean isolates and reference isolates

of the sample isolates resembled that of AG-1 IA.

From the results of the ISSR-PCR bands, hyphal fusion test, and colony morphology, these isolates were thought to belong to $R$. solani AG-1 IA.

\section{Field inoculation test to reproduce disease and DLS}

In inoculated plots, the same disease symptoms as seen in farmers' fields were reproduced. Leaf spots appeared within five days of inoculation, and the blight symptom gradually expanded to other leaves, causing defoliation. In severely affected plants, web-like mycelia and the abortion of pods were also observed. However, symptoms were limited to inside the canopy. The upper leaves remained relatively healthy, probably due to faster drying after overhead irrigation, making detection of the disease difficult. Even after inoculation, any occurrence of disease was marginal in non-irrigated plots, indicating the importance of rainfall for the disease to expand.

In inoculated and frequently irrigated plots without the application of fungicide, the incidence of disease and DLS was high; an average of $44 \%$ of the plants had severe DLS at harvest (Figs. 5, 6). When the aerial blight disease index exceeded 3 in late September, pod abortion was extensive and led to fewer pods at harvest and more severe DLS (Figs. $7,8)$. Without the application of fungicide, the yield of the diseased soybean plants was $12-35 \%$ lower than that in the noninoculated plots. Spraying with any fungicide during the pod-elongation period was effective in controlling DLS and yield loss. A similar result was obtained in a previous field inoculation test using the $R$. solani isolate GF1 from soybean, where the disease and DLS were well controlled by applying fungicide (data not shown).

From these results, Rhizoctonia aerial blight of soybean clearly led to delayed leaf senescence. Frequent rainfall (overhead irrigation) promoted disease development and the resulting DLS. 


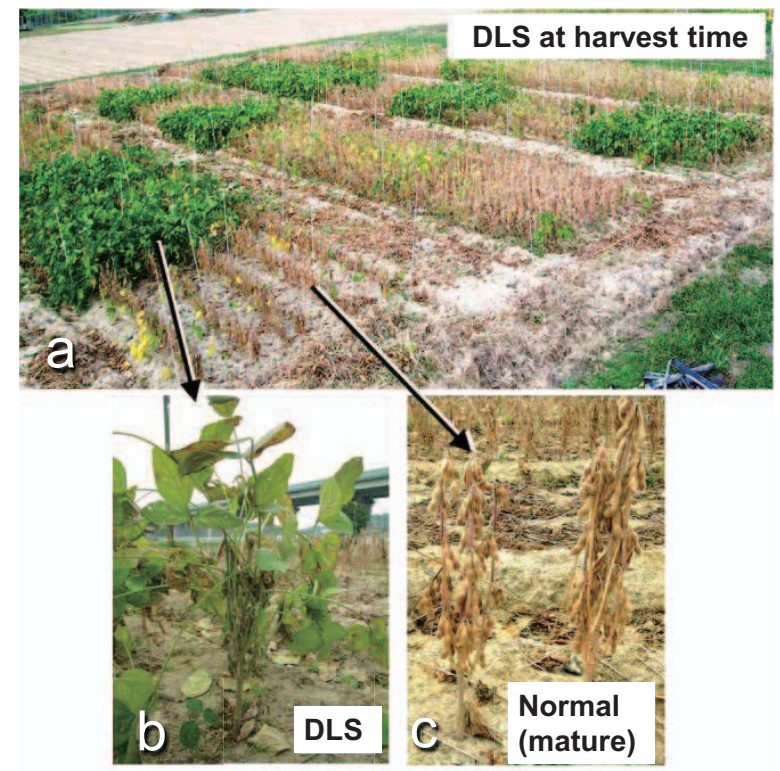

Fig. 5. Delayed leaf senescence (DLS) of soybean reproduced by field inoculation of rice sheath blight pathogen

(a) Field plots with DLS (green) and normal maturity (light brown)

(b) Soybean plant from a plot showing typical DLS symptoms

(c) Soybean plant from a plot showing normal maturity

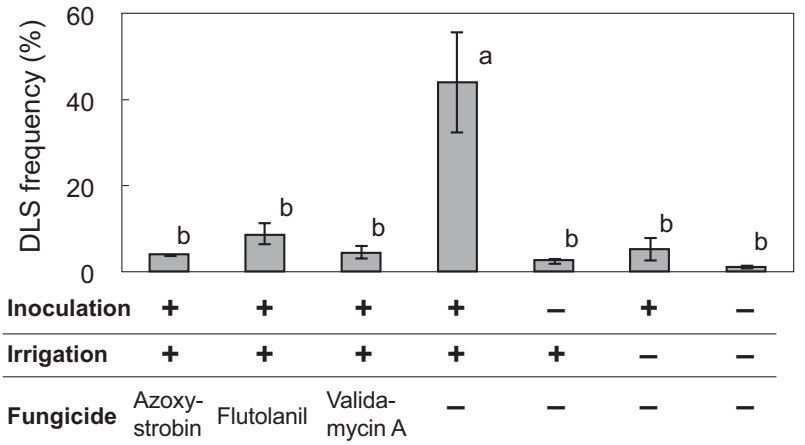

Fig. 6. Mean frequency of plants with DLS at harvest in plots with various treatments

Plants with DLS index 4 were regarded as DLS. Each bar represents a mean of three field plots $(4 \times 3 \mathrm{~m}$ each). Vertical lines represent the standard error. Values with the same letter did not differ significantly between treatments according to the Tukey-Kramer honestly significant difference (HSD) test (5\% level).

\section{Discussion}

Delayed leaf senescence (DLS) of soybean is a serious problem in many areas of the world, including Japan. Although the mechanism underlying DLS is not fully understood, some studies have indicated that removing soybean

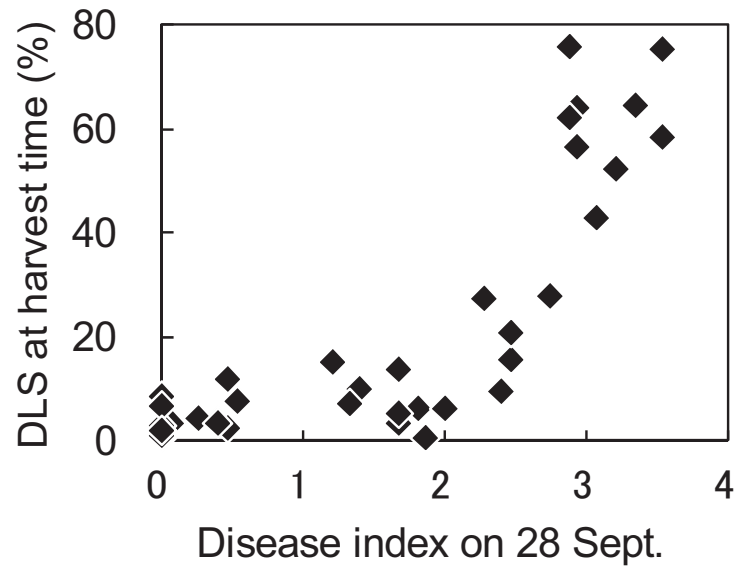

Fig. 7. Relationship between Rhizoctonia aerial blight disease index and DLS occurrence

Each plot corresponds to a $4 \times 3 \mathrm{~m}$ field plot. Only plants with DLS index 4 were regarded as DLS.

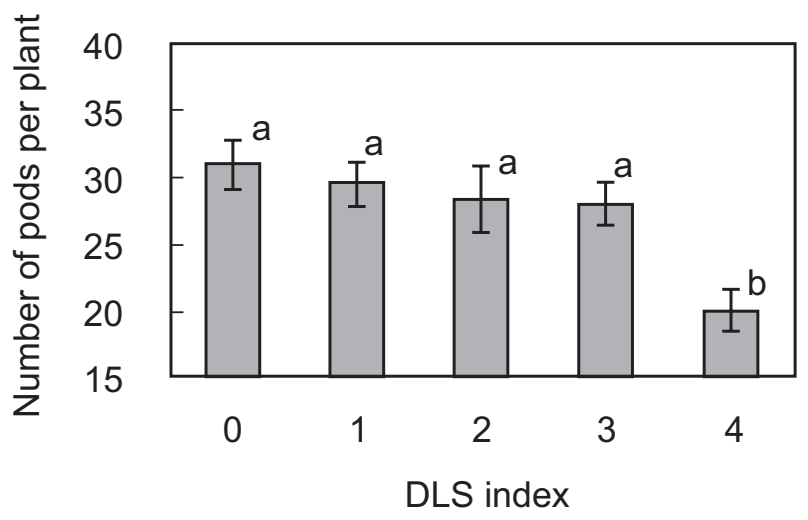

Fig. 8. Mean number of pods per soybean plant according to the DLS index for plants at harvest

The number of pods with seeds at harvest was counted for 18-32 plants with each DLS index. Vertical lines represent the standard error. Indices with the same letter did not differ according to the Tukey-Kramer HSD test $(5 \%$ level).

flowers or pods can delay senescence (Crafts-Brandner, et al. 1984, 1987). Stinkbugs have also been shown to contribute to DLS, perhaps by reducing the number of healthy pods (Boethel et al. 2000). These studies indicate that DLS results from an imbalance in nutrient acquisition between the source (leaves and roots) and sink (pods). In our study, in inoculated and frequently irrigated plots without the application of fungicide, the incidence of disease and DLS was high, and the number of pods was lower than that in healthy plants. Therefore, the decrease in pods caused by aerial blight disease may have led to DLS. From our observation, when the aerial blight disease index exceeds 3, pod abortion was extensive and led to more severe DLS. Thus, our study showed that Rhizoctonia aerial blight is at least one of the causes of soybean DLS. We also showed that 
agrochemicals already registered for soybeans, although against other diseases, hold promise for controlling aerial blight and the resulting DLS. The registration of those chemicals for the disease in Japan is thus highly desirable.

Regarding the relationship between the pathogens that cause rice sheath blight and Rhizoctonia aerial blight of soybean, a very early study by Yokogi (1927) in Japan had already suggested that the two pathogens are identical (at that time, Hypochnus sasakii Shirai). Later studies (Wu \& Lin 1967, Tsuzaki et al. 1995, Arai et al. 2000) also suggested that the same population of Rhizoctonia solani AG-1 IA could possibly cause both diseases. However, given the difficulty in distinguishing the AG-1 subgroups and the lack of phylogenetic evidence, the identity at the anastomosis subgroup level and its ecological importance have yet to be clarified. In the present study, we verified the identity of the pathogen at the subgroup level by using a molecular method-ISSR-PCR.

In Japan, soybeans have been cultivated with rice in close proximity (often in the same paddy field) since ancient times. Thus, the identity of both pathogens as subgroup AG-1 IA of Rhizoctonia solani is not very surprising. Although information on the incidence of rice sheath blight in the same field in the previous year (2003) is lacking, the occurrence of rice sheath blight in the area was very high in 2004. In their study on the outbreak of Rhizoctonia aerial blight of soybean in Kagawa Pref., Japan, Tsuzaki et al. (1995) also mentioned the crop rotation of soybeans with rice, and presumed that sclerotia remaining in soil after the rice sheath blight would be the primary source of inoculum for soybean disease. However, a study in the United States suggested a divergence between the soybean- and riceinfecting populations of AG-1 IA (Bernardes de Assis et al. 2008). Thus, more extensive studies using molecular markers (Arakawa \& Inagaki 2014) may be needed to elucidate the exact dynamics or interaction between the soybean- and rice-infecting populations in Japan.

An investigation of environmental factors that affect the incidence and severity of disease will also be important. In the case of Hiroshima in 2004, frequent rainfall and typhoons may have promoted the disease. In that year, rainfall in the area in August exceeded 170\% of the amount in normal years, while temperature was higher and the duration of sunshine lower. The meteorological conditions probably favored development of the disease. In addition, exceptionally frequent attacks by typhoons in 2004 (targeting Hiroshima four times) might have been another factor behind the outbreak, dispersing such inoculum as mycelia and infected leaves.

In this study, the causal pathogen of Rhizoctonia aerial blight in Hiroshima was AG-1 IA. In other studies, however, AG-1 IB and AG-2-3 were also identified as causing similar diseases (Yang et al. 1990, Naito \& Kanematsu
1994). Further study is needed to investigate the distribution of those strains in Japan. In addition, the possible involvement of the perfect stage (basidiospores) of the pathogen (Naito et al. 1995), which was not found in this study, may also be of interest.

\section{Acknowledgements}

We wish to thank Dr. Jun Isota of the Shimane Agricultural Technology Center for generously contributing strains of rice sheath blight pathogen used in this study. We also wish to thank Dr. Hiroyuki Takeda, Dr. Atsushi Kikuchi, Nobuyuki Matsuoka, Katsufumi Monden, and other staff members at the NARO/WARC for their technical assistance in the field experiments. Finally, we would also like to thank the researchers in Hiroshima Pref., especially Kiyoshi Sato, Hideki Terada, Hiromi Iwamoto, Taisaku Mise, and Makoto Nagato, for supplying us with precious information and diseased samples from the prefecture. This work was partly supported by a grant from Japan's Ministry of Agriculture, Forestry and Fisheries.

\section{References}

Arai, M. et al. (2000) Severe occurrence of Rhizoctonia aerial blight of soybean in Joetsu area of Niigata Prefecture. Hokuriku Byougaichuu Kenkyuu Kaihou (Proceedings of the Association for Plant Protection of Hokuriku), 48, 64 [Abstract in Japanese].

Arakawa, M. \& Inagaki, K. (2014) Molecular markers for genotyping anastomosis groups and understanding the population biology of Rhizoctonia species. J. Gen. Plant Pathol. 80: 401-407.

Atkins Jr., J. G. \& Lewis, W. D. (1954) Rhizoctonia aerial blight of soybeans in Louisiana. Phytopathology 44:215-218.

Bernardes de Assis, J. et al. (2008) Divergence between sympatric rice- and soybean-infecting populations of Rhizoctonia solani anastomosis group-1 IA. Phytopathology 98, 13261333.

Boethel, D. J. et al. (2000) Delayed maturity associated with southern green stink bug (Heteroptera: Pentatomidae) injury at various soybean phenological stages. J. Econ. Entomol. 93, 707-712.

Carling, D. E. et al. (1988) Relatedness within and among intraspecific groups of Rhizoctonia solani: A comparison of grouping by anastomosis and by DNA hybridization. Phytoparasitica 16, 209-210.

Crafts-Brandner, S. J. et al. (1984) Effects of pod removal on metabolism and senescence of nodulating and nonnodulating soybean isolines. I. Metabolic constituents. Plant Physiol.75, 311-317.

Crafts-Brandner, S. J. \& Egli, D. B. (1987) Sink removal and leaf senescence in soybean. Cultivar effects. Plant Physiol. 85, 662-666.

Domsch, K. D. et al. (1993) Compendium of Soil Fungi 1. IHWVerlag, Eching, Germany. 765-771.

Fujii, K. et al. (2015) Stability verification of the effects of stem determination and earliness of flowering on green stem disor- 
der of soybean against genetic background and environment. Plant Prod. Sci. 18, 166-179.

Isobe, K. et a1. (2014) Effects of early sowing cultivation on yield and occurrence of delayed stem senescence in several soybean cultivars in south Kanto. Nihon Sakumotsu Gakkai Kiji (Jpn. J. Crop Sci.) 83, 195-202 [In Japanese with English summary].

Kiyoshi T. et al. (2005) Analysis of genetic variation among subgroups of Rhizoctonia solani anastomosis subgroup 2 (AG-2) by inter-simple sequence repeat (ISSR) -PCR. Kitanihon Byougaityuu Kenkyuu Kaihou (Annual Report of the Society of Plant Protection of North Japan) 56, 34-37 [In Japanese with English summary].

Kurata, H. (1960) Web blight of soybean and its causal pathogen. In Studies on fungal diseases of soybean in Japan, Bulletin of the National Institute of Agricultural Sciences, Ser. C, 12, 97-153 [In Japanese with English summary].

Matsumoto, S. et a1. (1986) The occurrence of delayed stem maturation in early soybean varieties and a method for visual distinction. Japan. Jour. Crop Sci. 55 (3): 333-338 [In Japanese with English summary].

Naito, S. \& Kanematsu, S. (1994) Characterization and pathogenicity of a new anastomosis subgroup AG-2-3 of Rhizoctonia solani Kühn isolated from leaves of soybean. Ann. Phytopath. Soc. Japan 60, 681-690.

Naito, S. et al. (1995) Infection with basidiospores of Thanatephorus cucumeris (AG-2-3 of Rhizoctonia solani) and development of soybean foliar blight lesions. Ann. Phytopath. Soc. Jpn. 61:362-368.

Ochi, S. et al. (2005) Identification of the anastomosis group of Rhizoctonia solani isolates from soybean plants with foliar blight symptoms which were grown in upland fields converted from paddy fields. Jpn. J. Phytopathol. 71, 217-218 [Abstract in Japanese].

Ogiwara, H. (2002) Chapter 3. Cultivation technique, Section 11. Delayed leaf senescence. In Soybean : technical development for improving national food self-sufficiency ratio, Annotated bibliography of agriculture, forestry and fisheries research. ed. Agriculture, Forestry and Fisheries Research Council of Japan, Tokyo, No. 27:291-294 [In Japanese].

Ogoshi, A. (1976) Studies on the grouping of Rhizoctonia solani
Kühn with hyphal anastomosis and on the perfect stages of groups. Bull. Nat. Inst. Agr. Sci. Ser. C. 30, 1-63 [In Japanese with English summary].

Ogoshi, A. (1987) Ecology and pathogenicity of anastomosis and intraspecific groups of Rhizoctonia solani Kühn. Annual Review of Phytopathology 25, 125-143.

Takehara, T. et al. (2005) Occurrence of foliar blight and delayed leaf senescence of soybean caused by Rhizoctonia sp. in rotational soybeans at paddy fields. Jpn. J. Phytopathol. 71, 217 [Abstract in Japanese].

Takehara, T. et al. (2006) Methods for fungicide test on Rhizoctonia aerial blight of soybean caused by Rhizoctonia solani AG-1 IA. Jpn. J. Phytopathol. 72, 247 [Abstract in Japanese].

Tsuzaki, Y. et al. (1995) Occurrence of foliage blight of soybean caused by Rhizoctonia solani Kühn in Kagawa Prefecture. Shikoku Shokubutsu Boueki Kenkyuu (Proceedings of the Association for Plant Protection of Shikoku), 30, 33-38 [In Japanese].

Watanabe, B. \& Matsuda, A. (1966) Studies on the grouping of Rhizoctonia solani Kühn pathogenic to upland crops. Shitei Shiken (Byougaichuu) (Appointed Experiment (Plant diseases and pests) Bulletin) No. 7, Agriculture, Forestry and Fisheries Research Council, Ministry of Agriculture and Forestry, Tokyo, and Ibaraki Agricultural Experiment Station, Ibaraki, Japan. pp.137 [In Japanese with English summary].

White, T. J. et al. (1990) Amplification and direct sequencing of fungal ribosomal RNA genes for phylogenetics. PCR protocols: a guide to methods and application (Innis, M.A., Gelfand, D.H., Sninsky, J.J. and White, T.J. eds.), Academic Press, London, UK. 315-322.

Wu, L.-C. \& Lin, Y.-S. (1967) Rhizoctonia aerial blight of soybean caused by Thanatephorus cucumeris (= Pellicularia sasakii). Memoirs Coll. Agric. Natl. Taiwan Univ. 9, 57-69.

Yang, X. B., et al. (1990) Types of Rhizoctonia foliar blight on soybean in Louisiana. Plant Dis. 74, 501-504.

Yokogi, K. (1927) Studies on Hypochnus diseases of soybean and the identity of Hypochnus sasakii Shirai from soybean and the rice sheath blight pathogen. Byochu-gai Zasshi (Journal of Plant Protection), 14, 146-158 [In Japanese]. 